\title{
EPIDEMIOLOGICAL TRENDS, KNOWLEDGE AND PRACTICES OF ANIMAL BITE IN CHILDREN ATTENDING OUTPATIENT DEPARTMENT OF REWA CITY- A HOSPITAL BASED SURVEY
}

\author{
Neera Marathe1, Sanjeev Kumar ${ }^{2}$
}

${ }_{1}^{1}$ Associate Professor, Department of Community Medicine, Shyam Shah Medical College, Rewa, Madhya Pradesh, India.

${ }^{2}$ Assistant Professor, Department of Community Medicine, Government Medical College, Datia, Madhya Pradesh, India.

\begin{abstract}
BACKGROUND
ABSTRACT

Dog bites account for tens of millions of injuries annually with children being at the highest risk. Dog bite fatality rates are higher in low- and middle-income countries due to prevalent rabies virus, lack of post-exposure treatment and appropriate access to health care. Between $30 \%$ and $60 \%$ of the victims of dog bites are children under the age of 15 in countries where rabies is endemic.

The objectives of this study were-1. to assess the sociodemographic profile of animal bite victims who are $<15$ years old, 2 . To evaluate parents' knowledge and practices for prevention and control of rabies.
\end{abstract}

\section{MATERIALS AND METHODS}

This is institutional based cross-sectional observational study carried out among animal bite victims attending OPD of GMH, SGMH and District Hospital of Rewa city from February 2014 to February 2015. Out of 406 victims interviewed, 72 were $<15$ years of age (17.7\%). Data was analysed using Graph Pad software. Percentage and proportion were used for data analysis.

\section{RESULTS}

$17.7 \%(n=72)$ of cases were aged $<15$ years. $73.6 \%$ were males and $59.7 \%$ were urban residents. $61.1 \%$ victims belonged to below poverty line families. $94.4 \%$ victims sustained dog bites. Most common site of bite was lower extremity ( $38.9 \%$ ), followed by head and neck (30.6\%). Majority of the victims $84.7 \%$ had Category III bites. Almost half were bitten by pet animal/ or animal in vicinity of their home. $100 \%$ parents knew that animal bite would lead to rabies. Three fourths of them knew about washing the wound with soap and water. Availability of ARV Injection free of cost was known to almost $60 \%$ of them. Almost $60 \%$ of the victims after animal bite consulted to health personal. Wound washing was done in $62.5 \%$ of cases. Many (45.8\%) victims had taken advice from pharmacist. 55.6\% victims washed the wound within 1 hour and 51.4\% victims were administered ARV within 24 hours.

\section{CONCLUSION}

The adoption of PEP was below par in spite of having adequate knowledge of PEP. A delay in accessing PEP was noted. Present study revealed most victims approached health care personnel or pharmacist for advice. They can be utilized for sensitization of community emphasizing early initiation of post exposure prophylaxis measures. Time interval between animal bite and early initiation of PEP is crucial for prevention of rabies. Health educational program for community and pet owners focusing on vaccination of pets, supervision of children while playing with pets can be developed and implemented through grass root level workers and community leaders.

\section{KEY WORDS}

Rabies, Dog Bite, Children, India, Knowledge and Practices, Post Exposure Prophylaxis

HOW TO CITE THIS ARTICLE: Marathe N, Kumar S. Epidemiological trends, knowledge and practices of animal bite in children attending outpatient department of Rewa City- a hospital based survey. J. Evolution Med. Dent. Sci. 2019;8(10):667-670, DOI: $10.14260 /$ jemds/2019/148

\section{BACKGROUND}

Rabies is an acute, highly fatal viral disease of the central nervous system, caused by Lyssavirus type 1 . It is primarily a zoonotic disease of warm-blooded animals such as dogs, cats, jackals and wolves. Dogs are the main host and transmitter of disease.[1] An estimated 59000 people die annually from rabies globally, and bites from rabid dogs account for the majority of these deaths. Dog bites account for tens of millions of injuries annually children being at the highest risk.

\section{'Financial or Other Competing Interest': None.}

Submission 02-02-2019, Peer Review 23-02-2019,

Acceptance 25-02-2019, Published 11-03-2019.

Corresponding Author:

Dr. Sanjeev Kumar,

Assistant Professor, Department of Community Medicine,

Government Medical College,

Datia, Madhya Pradesh, India.

E-mail: dr.sanjeev19@gmail.com

DOI: $10.14260 /$ jemds $/ 2019 / 148$
Dog bite fatality rates are higher in low- and middleincome countries due to prevalent rabies virus, lack of postexposure treatment and appropriate access to health care. ${ }^{[2]}$ Between $30 \%$ and $60 \%$ of the victims of dog bites are children under the age of 15 in countries where rabies is endemic. ${ }^{[3]}$ The risk of injury to the head and neck is greater in children than in adults, which leads to increased severity, necessity for medical treatment and death rates. ${ }^{[4]}$ Many factors interact with each other which makes children more vulnerable for animal bite. Some of which include, the inability of the child to defend itself against dog, the inability of a child to accurately read nonverbal communication signals from a dog, the style of interaction a child directs to a $\mathrm{dog}$, size of the child and the interaction between a dog's behavioural tendencies and the cognitive/developmental stage of the child.[5] As rabies is $100 \%$ fatal but preventable, Post exposure prophylaxis of Rabies is of prime importance. Rabies is an endemic disease in country like India, dogmediated transmission is a great threat, every animal bite is suspected as a potentially rabid animal bite, and treatment 
should be started immediately after exposure. Post-exposure prophylaxis is a three-pronged approach that is management of wound, Passive immunization with Rabies Immunoglobulin (RIG) and Active immunization with AntiRabies Vaccines (ARV). All three carry equal importance and should be done simultaneously as per the category of exposure This can be attained by creating awareness in general community to seek (PEP)Post-exposure prophylaxis.[6] Various Studies (Give reference) has been done on dog bite mainly focused on profile and management of dog bites. This study has been carried out with the objective to assess sociodemographic profile of animal bite victims, their knowledge and practices for prevention and control of rabies. Although data collection has been done for children and adult population, this paper focuses on data pertaining to children less than 15-year age group and circumstances that lead to animal bite. Further, management of animal bite depend on parents, their knowledge was assessed for consequences of animal bite, preventive measures and immediate measures for animal bite they adopted was enquired.

\section{MATERIALS AND METHODS}

This is an institution based cross sectional observational study carried out among patients with animal bite attending OPD of GMH (Gandhi Memorial Hospital), SGMH (Sanjay Gandhi Memorial Hospital) and District Hospital of Rewa city (Madhya Pradesh) from February 2014 to February 2015. Sample size estimation was done by purposive sampling. About 400 sample size was estimated as sufficient to meet purpose of study by the researcher. However 406 victims were interviewed which corresponds to approximately $10 \%$ of last year animal bite victims registered.

Sample size was taken based on the conveniences of the study

Total 406 victims were interviewed out of which 72 were below 15-year age group (17.7\%)

\section{Study Variables}

1. Sociodemographic factors like age, sex, education of mother/ father and occupation of father, socioeconomic status.

2. Information pertaining to bite like pet/stray animal, site, category of bite, provoked/ unprovoked

3. Knowledge and practices regarding rabies and its prevention and control, PEP seeking behaviour after the exposure.

\section{Data Analysis}

Data was entered into excel sheet and analysed using Graph Pad software. Percentage and proportion were used to present data.

Data Collection Method: Data Collection was done by interviewing the subjects. Pre-testing was done and questionnaire was modified where needed. Interviewer visited the facility twice in a week and on that particular day all the victims presenting to OPD were explained the procedure and purpose of study. Questionnaire was administered only to those who gave informed consent. Local examination of wound was carried out to categorize the bite. Categorization of exposure was done as per WHO Guidelines.[7] Those who were below 18 years consent was obtained preferably from parents. If they visited health facility with their guardians other than parents, informed consent was obtained from them only. Parents/ Guardians were asked to take part in the study for circumstances of animal bite and their knowledge and practices.

\section{RESULTS}

$17.7 \%(\mathrm{n}=72)$ victims comprised children less than 15 years of age. The youngest age of the patient was a child, 10 months old in this study. $73.6 \%$ were males and $59.7 \%$ were urban residents. $41.7 \%$ victims have one or both parents attained primary education and above. Almost half of the fathers of the victims were laborers and daily wagers followed by selfemployed/business category. $61.1 \%$ victims belonged to below poverty line family. [Table-1] Majority (94.4\%) victims were bitten by dogs. Most common site of bite was lower extremity (38.9\%) followed by head and neck (30.6\%). Majority of the victims $84.7 \%$ had sustained Category III bites. Almost half were bitten by pet animal/ or animal in vicinity of their home and in $62.5 \%$ bites were provoked. [Table-2] Knowledge assessment was done by including key points in questionnaire which might result in better practices for PEP. All of the parents knew that animal bite leads to rabies. Three fourth of them knew about washing the wound with soap and water. Availability of ARV Injection free of cost was known to almost $60 \%$ of them. But knowledge for essentiality of immunoglobulins for Category III bite was quite poor among them. Only $6.9 \%$ aware of immunoglobulins. [Table-3] Almost $60 \%$ of the victims after animal bite consulted health personal. Wound washing was practiced by $62.5 \%$ of victims. Many (45.8\%) victims had taken advice from pharmacist. 55.6\% victims washed the wound within 1 hour and $51.4 \%$ victims were administered ARV within 24 hours. [Table-4 and 5]

\begin{tabular}{|c|c|c|}
\hline Sociodemographic Profile $(\mathrm{N}=72)$ & Number & Percentage \\
\hline \multicolumn{3}{|l|}{ Age } \\
\hline $0-5$ & 17 & $23.6 \%$ \\
\hline $6-15$ & 55 & $76.4 \%$ \\
\hline \multicolumn{3}{|l|}{ Gender } \\
\hline Male & 53 & $73.6 \%$ \\
\hline Female & 19 & $26.4 \%$ \\
\hline \multicolumn{3}{|l|}{ Residence } \\
\hline Rural & 29 & $40.3 \%$ \\
\hline Urban & 43 & $59.7 \%$ \\
\hline \multicolumn{3}{|c|}{ Education of Parents (Father/Mother/Both) } \\
\hline Illiterate and Primary & 42 & $58.3 \%$ \\
\hline$>5^{\text {th }}$ to $12^{\text {th }}$ & 25 & $34.7 \%$ \\
\hline Graduate and Above & 05 & $6.9 \%$ \\
\hline \multicolumn{3}{|c|}{ Occupation of Father } \\
\hline Unemployed & 11 & $15.3 \%$ \\
\hline $\begin{array}{c}\text { Agriculture Worker/ Labourer/Daily } \\
\text { Wager }\end{array}$ & 34 & $47.2 \%$ \\
\hline Govt/Private Service & 10 & $13.9 \%$ \\
\hline Self-Employed/ Business & 17 & $23.6 \%$ \\
\hline \multicolumn{3}{|c|}{ Socioeconomic Status } \\
\hline BPL* & 44 & $61.1 \%$ \\
\hline APL & 28 & $38.9 \%$ \\
\hline
\end{tabular}




\begin{tabular}{|c|c|c|}
\hline \multicolumn{3}{|l|}{ Animal } \\
\hline DOG & 68 & $94.4 \%$ \\
\hline OTHERS(Cat, Monkey, Pig, Cow) & 04 & $05.6 \%$ \\
\hline \multicolumn{3}{|l|}{ Site of Bite } \\
\hline Head and Neck & 22 & $30.6 \%$ \\
\hline Upper Extremity & 14 & $19.4 \%$ \\
\hline Lower Extremity Genitals, & 28 & $38.9 \%$ \\
\hline Chest, Abdomen, Multiple Sites & 08 & $11.1 \%$ \\
\hline \multicolumn{3}{|c|}{ Bitten by Pet/Animal in Vicinity } \\
\hline Yes & 35 & $48.6 \%$ \\
\hline No & 37 & $51.4 \%$ \\
\hline \multicolumn{3}{|l|}{ Category } \\
\hline I & 02 & $2.8 \%$ \\
\hline II & 09 & $12.5 \%$ \\
\hline III & 61 & $84.7 \%$ \\
\hline \multicolumn{3}{|c|}{ Provoked/Unprovoked } \\
\hline Provoked Bite & 45 & $62.5 \%$ \\
\hline Un Provoked Bite & 27 & $37.5 \%$ \\
\hline \multicolumn{3}{|c|}{ Table 2. Profile of Animal Bite } \\
\hline
\end{tabular}

\begin{tabular}{|c|c|c|}
\hline Knowledge & Number & \% \\
\hline $\begin{array}{c}\text { Animal bite leading to disease which } \\
\text { is fatal }\end{array}$ & 72 & $100 \%$ \\
\hline $\begin{array}{c}\text { Washing the wound with soap and } \\
\text { water }\end{array}$ & 55 & $76.4 \%$ \\
\hline $\begin{array}{c}\text { Availability of ARV Injection free of } \\
\text { cost }\end{array}$ & 43 & $59.7 \%$ \\
\hline Immunoglobulins given for cat. III & 05 & $6.9 \%$ \\
\hline
\end{tabular}

Table 3. Knowledge of Rabies and Post Exposure Prophylaxis

\begin{tabular}{|c|c|c|}
\hline Response/Action Taken & Frequency & $\mathbf{\%}$ \\
\hline $\begin{array}{c}\text { Consulted to Health Personnel } \\
\text { (Doctor, ANM, Staff Nurse) }\end{array}$ & 43 & $59.7 \%$ \\
\hline $\begin{array}{c}\text { Washed with Only Water/ Soap with } \\
\text { Water }\end{array}$ & 45 & $62.5 \%$ \\
\hline $\begin{array}{c}\text { Applied Antiseptic/ Local Antibiotic } \\
\text { Cream }\end{array}$ & 17 & $23.6 \%$ \\
\hline $\begin{array}{c}\text { Application of Haldi/Chuna/Red Chilli } \\
\text { Powder/ Pan Leaf/ Milk/ Herbal } \\
\text { Medication/Mud }\end{array}$ & 20 & $27.8 \%$ \\
\hline Tied the Wound with Cloth & 12 & $16.7 \%$ \\
\hline Consulted Quack/ Baba & 07 & $9.7 \%$ \\
\hline Consulted Pharmacist & 33 & $45.8 \%$ \\
\hline
\end{tabular}

Table 4. Immediate Measures Taken for Wound Care after Animal Bite* $(\mathrm{N}=72)$

*Multiple response

\begin{tabular}{|c|c|c|}
\hline $\begin{array}{c}\text { Time Interval after Animal Bite and Washing } \\
\text { with Soap and Water/only Water }\end{array}$ & No. & $\%$ \\
\hline Immediately-<1 hr. & 40 & $55.6 \%$ \\
\hline 1 hr.-6 hrs. & 27 & $37.5 \%$ \\
\hline$>6$ hrs. & 05 & $6.9 \%$ \\
\hline Time Interval for Initiation of ARV & & \\
\hline$<24$ hrs. & 37 & $51.4 \%$ \\
\hline 24 hrs- 72 hrs. & 28 & $38.9 \%$ \\
\hline 1 week-1 month & 07 & $9.7 \%$ \\
\hline $\begin{array}{c}\text { Table 5. Time Interval Between Animal Bite and Washing } \\
\text { with Soap and Water/ Only Water and Initiation of ARV } \\
\text { (n=72) }\end{array}$ \\
\hline
\end{tabular}

\section{DISCUSSION}

As per our literature review, we found that there are limited studies available on epidemiology and management of animal bite in children. Hence, the present study was undertaken to explore factors associated with animal bite in children, which, is a vulnerable population. Amongst 406 victims interviewed, 72 were below 15 years of age (17.7\%). Another institution based study from India by Sridhar P et al, [8] reported 33.8\% of animal bite victims were below 15 years of age. While Shankar S et al[9] reported $26.4 \%$ victims were aged 19 years. Another Community based study revealed, $33.6 \%$ children had exposure to animal bite.[10] Almost $60 \%$ of the animal bite victims belonged to urban area in the present study. This is in contrast to another study, which reported almost 79\% victims belonged to rural area. ${ }^{[8]}$ This may be due to different the study settings and period. Male preponderance was seen in the present study (73.6\%).Similar findings were reported in other studies.[11,12] Although Sankar S[9] reported almost equal presentation among both genders. $61.1 \%$ victims belonged to below poverty line family. This is consistent with other studies $[8,13] 94.4 \%$ victims were inflicted by dogs. This finding is consistent with various studies[8-14] Most common site of bite was lower extremity followed by head and neck (30.6\%).This is in accordance with various studies. However, this was followed by upper limb injury.[8,13] One study reported children below 5 years had significantly greater incidence of bites on face and trunk than children more than 5 years of age.[15] This may be attributed to their playful nature, running at sight of dogs and short stature. Majority of the victims $84.7 \%$ had Category III. Similar finding was observed in other studies[8,11,13] Although Kale et al[16] reported Category II Bite as most common. This finding warrants immediate provision of PEP as Category III bites, which are life threatening. Almost half victims were bitten by pet animal and in $62.5 \%$ bites were provoked. Kale et al reported $60.5 \%$ of dog bites were by pet dogs while Kavya et al reported [11] 66\% bite by stray dogs. Many studies found proportion of provoked bite lower than the present study. This may be due to the different study setting and population. $[13,17,18]$ Sridhar $P$ et al ${ }^{[8]}$ concluded high proportion of provoked bites (71.4\%). This finding suggest sensitization of dog owner about importance of proper vaccination of their pets, supervision of children while playing with pets and orient their children about dog behaviour. This might provide some protection against rabies. Knowledge aspect in the present study was sufficiently higher than the other studies.[9,14] This might be due to increased awareness of rabies and availability of PEP in urban population. Studies from urban areas corroborate this finding.[19] Present study found that $62.5 \%$ of victims practiced wound washing. Various studies reported similar finding. ${ }^{[8,13,19]}$ Children received prompt medical attention, including PEP prophylaxis. Severity of bites in children and concern on the part of parents, and neighbours might be responsible for early initiation of PEP. Studies from other parts of India revealed delayed wound washing and delayed initiation of ARV.[11,12] Although present study showed increased awareness but didn't reciprocate it into practices so far.

\section{Limitation of The Study}

This was institution-based study for limited duration. The purposive sampling adopted may hinder the generalizability of the study. 


\section{CONCLUSION}

The adoption of PEP was below par in spite of having adequate knowledge of PEP. A delay in accessing PEP was noted. Present study revealed that most victims approached health care personnel or pharmacist for advice. They can be utilized for sensitization of community emphasizing early initiation of post exposure prophylaxis measures. Time interval between animal bite and early initiation of PEP is crucial for prevention of rabies. Health educational program for community and pet owners focusing on vaccination of pets, supervision of children while playing with pets can be developed and implemented through grass root level workers and community leaders.

\section{REFERENCES}

[1] Park K. Park's Textbook of Preventive and Social Medicine. 24th edn. Jabalpur: M/s Banarasidas Bhanot Publishers 2017: p. 294-5.

[2] WHO. Animal bites. (cited 12.01.2019) https://www.who.int/news-room/factsheets/detail/animal-bites

[3] Patralekha Chatterjee reports. WHO. India's ongoing war against rabies. (Cited 22.01.2019). https://www.who.int/bulletin/volumes/87/12/09021209/en/

[4] Kole AK, Roy R, Koleb DC. Human rabies in India: a problem needing more attention. Geneva: 2014 [cited 27.01.2019]

http://who.int/bulletin/volumes/92/4/14136044.pdf

[5] Polsky RH. CDBC Los Angeles, California. Animal behaviour expert on dog bite attacks. (cited 27.01.2019). https://www.dogexpert.com/dog-bitestatistics-for-children/

[6] National Rabies Control Programme. National Guidelines on Rabies Prophylaxis. (Cited 28.01.2019). http://pbhealth.gov.in/guideline\%20for\%20rabies\% 20prophylasix.pdf

[7] WHO guide for post exposure prophylaxis. (Cited 28.01.2019). http://www.who.int/rabies/ human/postexp/en/.

[8] Sridhar PV, Shanmukappa, Vinay M, et al. Profile of children bitten by dogs, reporting to a government tertiary care hospital and their compliance to post exposure prophylaxis. Journal of Evolution of Medical and Dental Sciences 2014;3(43):10673-8.
[9] Shankar S, Raghuram V, Krishnakumar M, et al. A study on assessing the knowledge, attitude \& practice among the victims of animal bites in Trichy, Tamil Nadu. Nat J Res Community Med 2018;7(1):47-51.

[10] Krishna C, Syiem N, Nongbet N, et al. Health seeking behaviours of individuals exposed to animals. Nat J Res Community Med 2019;8(1):31-5.

[11] Kavya MA, Shobha, Ranganath TS, et al. Profile of pediatric animal bite cases in Victoria hospital, Bengaluru: a cross sectional study. Nat J Res Community Med 2019;8(1):46-9.

[12] Sheetal V, Kinnari G, Gneyaa B, et al. Animal bite management practices: study at three municipal corporation hospitals of Ahmedabad. Nat J Comm Med 2010;1(2):75-8.

[13] Venkatesan M, Dongre A, Ganapathy K. A community based cross sectional study of dog bites in children in a rural district of Tamil Nadu. International Journal of Medical Science and Public Health 2017;6(1):109-12.

[14] Kakrani VA, Jethani S, Bhawalkar J, et al. Awareness about dog bite management in rural population. Indian Journal of Community Health 2013;25(3).

[15] Samanta M, Mondal R, Shah A, et al. Animal bites and Rabies prophylaxis in rural children: Indian perspective. Journal of Tropical Pediatrics 2016;62(1):55-62.

https://doi.org/10.1093/tropej/fmv072

[16] Kale KM, Wadhva SK, Aswar NR, et al. Dog bites in children. Indian J Community Med 2006;31(1):245. http://www.ijcm.org.in/text.asp?2006/31/1/24/54 927

[17] Behera TR, Satapathy DM, Tripathy RM, et al. Profile of animal bite cases attending the ARC of M.K.C.G. Medical College, Berhampur (Orissa). APCRI J 2008;9(2).

[18] Ichhpujani RL, Mala C, Veena M, et al. Epidemiology of animal bites and rabies cases in India. A multicentric study. J Commun Dis 2008;40(1):27-36.

[19] Sharma S, Agarwal A, Khan AM, et al. Prevalence of dog bites in rural and urban slums of Delhi: a communitybased study. Ann Med Health Sci Res 2016;6(2):115-9. 